\title{
Solar Powered Low Voltage Pump Display
}

\author{
Ravi Kumar P., Akash B., Hari Krishnan R., Lakshmi Narayanan S., Arunodhayan N.
}

\begin{abstract}
Water, a major source of life and a treasure of great demand in near future that needs more attention that it is already given. Electricity is another important resource that acts as a basic need to accomplish every single industrial application and new innovations. Our project is a solution that aims to get optimum use of both these resources. While using pumps there are possibilities of wastage of current. Some of the common cases are where the current is drawn from the grid but the water actually doesn't flow through the pump or the current drawn is comparatively more than the water flowing through pump. The motor works efficiently when both the current drawn from the grid and the water flow through the pipe are same. Our system consists of an LCD which displays the current drawn, voltage and the speed of the water flow. These are detected through current sensor, voltage sensor and water flow sensor. So by looking at the LCD screen we will be able to find out if the current is drawn unnecessarily without the actual flow of water and thereby we can prevent wastage by switching off the motor. The same can be done in the case where more current is drawn for less water. We will find the fault in the motor through this and rectify it. Thus this projects prevents wastage of electricity while using water pumps in industries.
\end{abstract}

Keywords: Pumps, LCD, Renewable, display, Automation, Arduino

\section{INTRODUCTION}

Pumps play vital role in everyday life, so it essential to display the electric parameter consumed by pumps while operating .Our project is to design the display unit for the pumps and make the low voltage pump to operate using solar energy. This methodology helps in reducing the cost for the installation of a separate pump managing panel and will make use of renewable source.

A solar water pumping system is designed with solar photovoltaic panel and locally available electric pumps. All components in the system design have been procured locally except solar panels. The other major component of this system is the pump. Solar water pumps are specially designed to use solar power efficiency .Low volume pumping keeps the cost of the system down by using a minimum number of solar power efficiency

Revised Manuscript Received on August 30, 2020.

* Correspondence Author

Ravi Kumar P.*, EEE, KPR Institute of Engineering and Technology Cioimbatore, India. E-mail: ravikumar.p@kpriet.ac.in

Akash B., EEE, KPR Institute of Engineering and Technology Cioimbatore, India. E-mail: bakayoak@gmail.com

HariKrishnan R., EEE, KPR Institute of Engineering and Technology Cioimbatore, India. E-mail: krish7798@gmail.com

LakshmiNarayanan S., EEE, KPR Institute of Engineering and Technology Cioimbatore, India. E-mail: massvetri13898@gmail.com

Arunodhayan N., EEE, KPR Institute of Engineering and Technology Cioimbatore, India. E-mail: arunodhayan34@gmail.com

(c) The Authors. Published by Blue Eyes Intelligence Engineering and Sciences Publication (BEIESP). This is an open access article under the CC BY-NC-ND license (http://creativecommons.org/licenses/by-nc-nd/4.0/)

\section{PROPOSED MODEL}

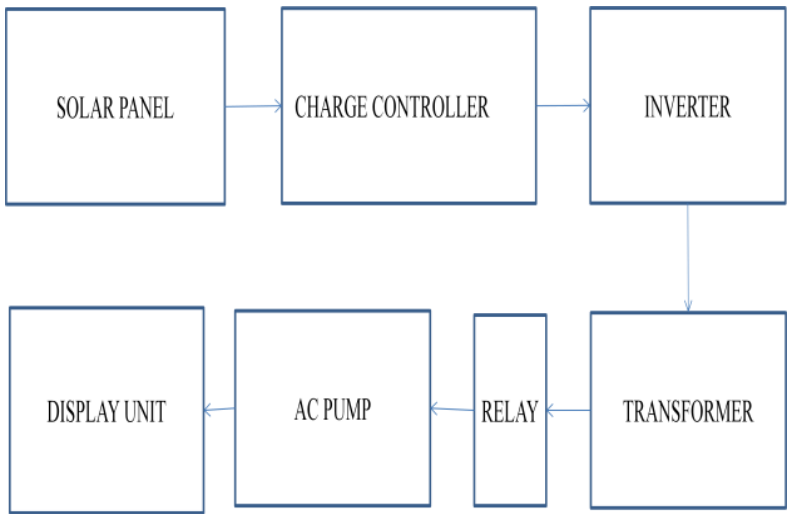

Fig. 1.System Flow Diagram of the Proposed model

Figure 1. . Shows the proposed block diagram of the project. It consist of the following components, Solar panel, Charge controller, Voltage sensor, current sensor, Arduino controller, motor , Pressure sensor, water flow .

\section{RELATED WORK}

\section{A. Solar powered water pumping system}

A solar high-powered water pumping system is created of 2 basic elements. the littlest component of a PV panel is that the electric cell. every electric cell has 2 or additional specially ready layers of semiconductor material that turn out DC (DC) electricity once exposed to light-weight. This DC current is collected by the wiring within the panel. it's then equipped either to a DC pump, that successively pumps water whenever the sun shines, or hold on in batteries for later use by the pump. The aim of this text is to elucidate however star high-powered water pumping system works and what the variations with the opposite energy sources area.

\section{B. IoT based solar water pumping system}

In this system, star panels manufacture a right away current, which might be reborn into AC by the convertor and utilized in home, industrial and agriculture applications. The output of the panels depends on the direction of sun's rays (solar energy), and therefore the star solar cell converts the alternative energy into helpful electricity. The aim of this paper is to develop the star electrical phenomenon generation system supported a typical power natural philosophy cell for small industrial, commercial, home yet as agriculture applications. The planned system is capable to supply protection from wind and rain, thereby the potency of the star panels can increase. The generation of the electricity is a lot of with trackers than stationary counterparts because of direct exposure to sun's rays. This increase is the maximum amount as twenty fifth relying upon the geographic location of the chase system.

Published By:

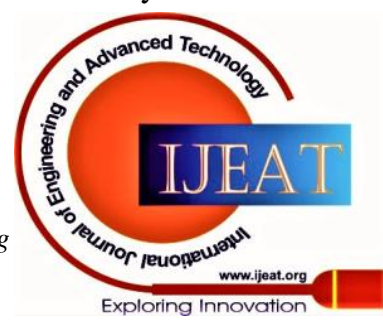




\section{Solar Powered Low Voltage Pump Display}

The generated output voltage is used for numerous functions, and that we used the shop energy to run Associate in Nursing agriculture pump by exploitation the net of things (IoT)

\section{Arduino based solar water pump auto-irrigation system}

With agriculture being the first economic sector of Asian country and alternative developing countries, it's the urge of the hour to automates it so as to extend potency Automation considerably moderates the number of toil, and makes farming easier and quicker, leading to a lot of agricultural growth. This paper proposes the 3 major add agricultur field: the dual-axis sun trailing system for power generation to the optimum level and storing the energy in an exceedingly battery The pumps area unit analogized with DC motors and also the whole system is controlled by Arduino. The speed of motor is controlled manually by a Pulse breadth Modulation wave generated by AN Operational electronic equipment multi-vibrator circuit. The soil wet sensors, IR sensors and water level sensors area unit interfaced with Arduino to supply info regarding the prevailing setting conditions on the idea of that the microcontroller take necessary selections regarding turning on or off of DC motors

\section{PARAMETERS}

\section{A. Voltage}

A voltage device could be a device that associate in monitoring the quantity of voltage in an object .voltage device will confirm each the AC voltage or DC voltage level at the input of this device may be the voltage whereas the output is that the switches, analog voltage a current signal Sensors area unit primarily a tool which may sense or determine and react to bound forms of electrical or some optical signals. implementation of voltage device and current device techniques became a superb option to the traditional current and voltage periodic strategies.

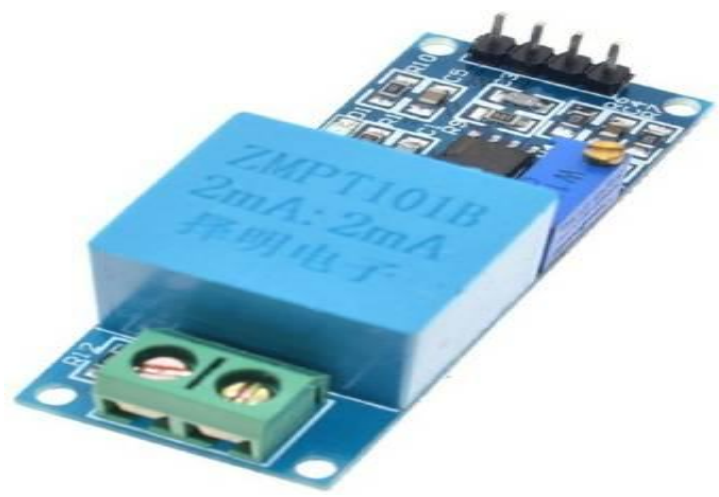

Fig.2.Voltage sensor

The voltage sensor block represents an ideal voltage sensor,

\section{B. Current}

A current sensing element may be a device that detects current in a every wire and generates an indication proportional to thereto current. This generate signal may be analog voltage or current or perhaps a digital output. The generated signal may be then accustomed and show the measured current in associate degree meter, or may be keep for any analysis in a knowledge acquisition system, or may be used for the aim of management.

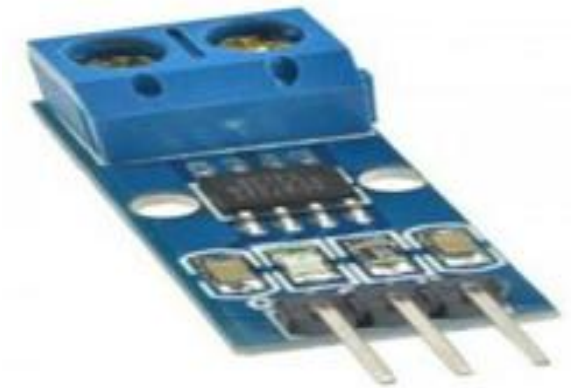

Fig.3.Current sensor

Figure 3 shows current sensor measuring current in a circuit a sensor is required, ACS712 current sensor is the sensor that can be used to measure and calculate the amount of current applied to the conductor without affecting the performance of the system.

\section{Solar panel design}

Normal Operating Cell Temperature (NOCT) The electrical device cells don't seem to be $77^{\circ} \mathrm{F}$. They heat up abundant hotter than that within the sun, overflow $100^{\circ} \mathrm{F}$. NOCT takes a additional realistic read of actual planet conditions, and offers you power ratings that you just can probably see from your scheme. Rather than one thousand watts per cent area, it uses 800 watts per cent area, that is nearer to a principally sunny day with scattered clouds. It uses associate degree air temperature of $20^{\circ} \mathrm{C}\left(68^{\circ} \mathrm{F}\right)$, not a cell temperature, and includes a a pair of.24MPH wind cooling the rear of a ground mounted electrical device (more common in larger star fields than a roof mounted residential array). These ratings are going to be less than STC, however additional realistic.

\section{Display}

LCD liquid show could be a sort of flat panel show that uses liquid in its primary sort of operation. LEDs have an outsized and ranging set of use cases for shopper and businesses, as they will be normally found in televisions, computer monitors and instruction panels liquid show technology works by obstruction light-weight. Specifically, a liquid crystal display is formed of 2 items of polarized glass (also referred to as substrate) that contain a liquid material between them. A backlight creates light-weight that passes through the primary substrate. Every screen contains a matrix of pixels that display the image on the screen. Whereas the liquid crystals block most of a LCD's backlight after the unit off, a number of the sunshine should still shine through (which can be noticeable in Therefore, OLEDs generally have darker black levels than LCDs

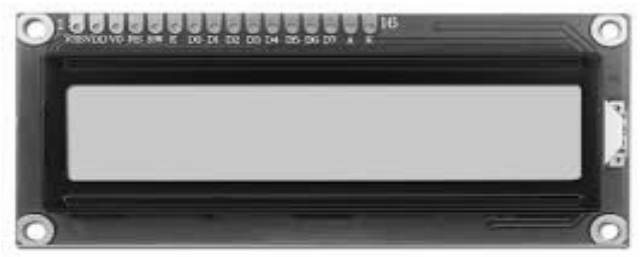

Fig.4.LCD display

Published By:

Blue Eyes Intelligence Engineering 
Figure 4 lcd display do not emit light directly instead using a backlight are reflector to produce images in color or monochrome.

\section{WORKING}

When the alternative energy drops sun rays on the PV panels then the solar battery converts the rays into voltage with the assistance of Si wafers mounted at intervals the PV panels. Then the alternative energy provides to the electrical motor to control the pumping system exploitation cables. By the revolution of the shaft that is mounted to the pump, then the pump begins to choose up the soil water and provides to the fields. When the energy is a smaller amount to choose up the water the facility boosting system and charge controller makes the pump operating with efficiency at low voltage condition. Therefore the total data of the system is connected to show unit by Arduino to look at the electrical parameters consumed by the system. Figure 5 shows about the hardware setup of show within the block

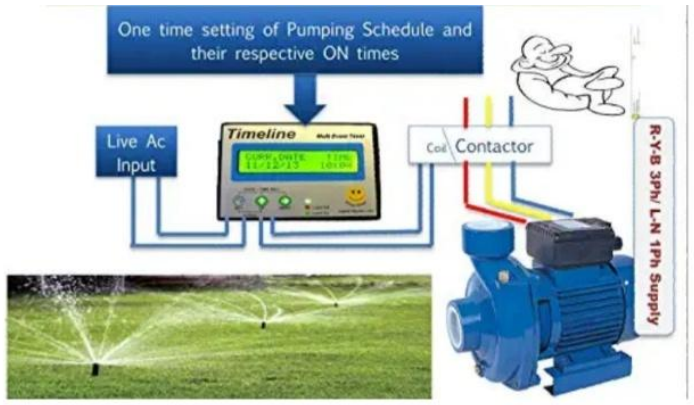

Fig.5.Display unit

\section{RESULTS}

Thus the required values of the current and voltage of the display. Hence it can be used to analyze the electrical values of the pump and to keep a constant check on the parameters.

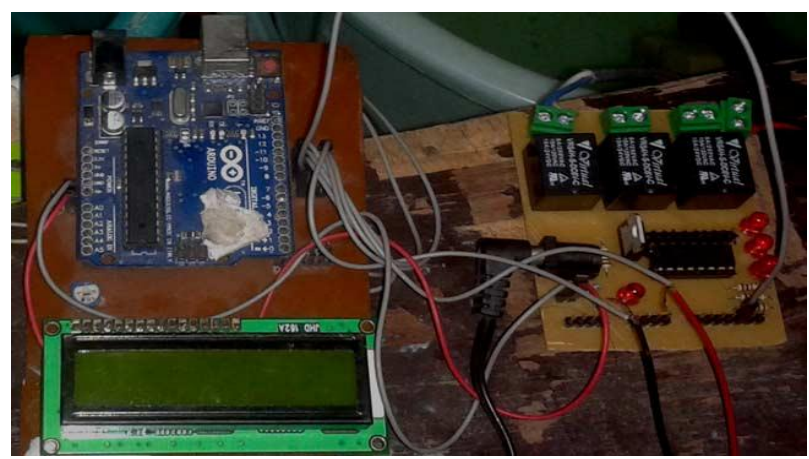

Fig. 6.Home screen

Figure 6 shows the hardware of the display unit which displays the electric parameter of the pump.

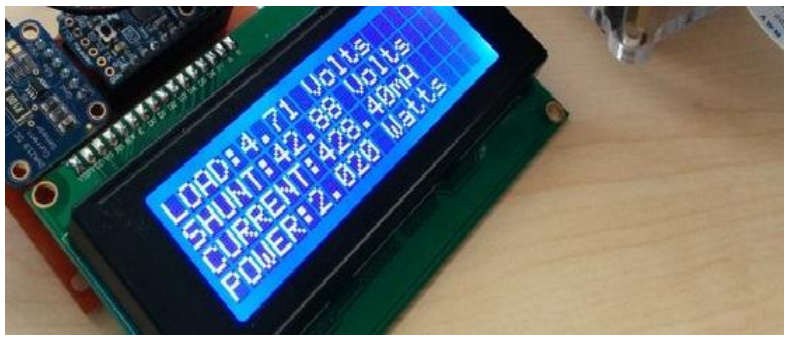

Fig.7.LCD output

Figure 7 display the voltage and the current consumed by pump has been noted and it has been displayed in the LCD

the load and it helps the user to understand the working and faults in the pump. Figure 8 shows about the graph plotted base on the amount of radiation on solar panel during different period of time

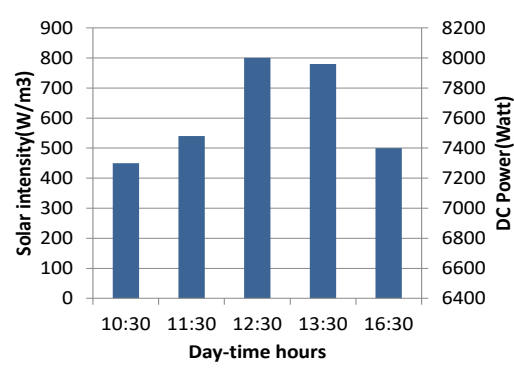

Fig.8.Output graph

\section{CONCLUSION AND FUTURE SCOPE}

The motor's current and voltage are often monitored through the display. This additionally indicates the flow of water within the pump through the flow device that is hooked up close to the gate valve. Once the motor attracts high current, and once the flow sensor's output is low it's a fault condition. once the motor attracts high current and therefore the flow sensor's output is additionally high ,then there's no fault condition. The output parameters shown within the show LCD digital display alphanumeric display helps user to see the motor's running condition. Also, if there's no output within the flow device it indicates there's no flow of water also because the motor's unessential run. thus at the tip, the motor's potency are often monitored by a personal through the display. The electrical phenomenon power is a lot of cost-competitive once accustomed power a small irrigation system as compared to associate overhead system. electrical phenomenon power for pump is costcompetitive with ancient energy sources for little, remote applications, if the overall system style and utilization temporal order is fastidiously thought of and arranged to use the alternative energy as with efficiency as potential. within the future values of fossil fuels rise and therefore the economic blessings of production cut back the height watt cost of the solar cell, electrical phenomenon power can become a lot of cost-competitive and a lot of common.

\section{REFERENCES}

1. Saadi, A. Moussi (2007), “Optimisation of Back-boost converter by MPPT Techniquewith a Variable Referance Voltage Applied to Photovoltaic Water Pumping System under Variable Weather condition," Asian Journal of Information Technology, volume 6. 2, pp. 222-229.

2. S. Parvathy and A. Vivek(2015), "A Photovoltaic Water Pumping System with High Efficiency and High Lifetime", Proceedings of IEEE International Conference on Technological Advancements in Power and Energy TAP Energy, pp. 489-493.

3. K. B. Rohit, G. M. Karve and Khatri(2013), "Solar Water Pumping System", IJETAE., vol. 3, no. 7, pp. 323-337.

4. Mapurunga Caracas, Farias De Carvalho, Moreira Teixeira and Souza Ribeiro(2014),

"Implementation of a High Efficiency high Life Time and low cost converter for an autonomous photovoltaic water and Sciences Publication

(C) Copyright: All rights reserved.

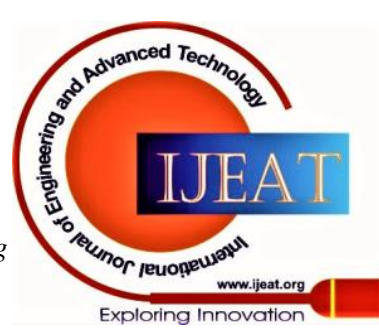


pumping system", IEEE Trans. Ind. Application, vol. 50, no. 1, pp. 631-641.

5. S. R. Shaikh and A. M. Jain(2015), "A high efficient converter for photovoltaic water pumping system", ICCICCT, pp. 522-526

6. Srushti R. Chafle and Uttam B. Vaidya(2013), "Incremental Conductance MPPT technique for PV system", IJAREEIE., vol. 2, no. 6, pp. 2719-2726.

7. S. I. Khan, M. M. Sarkar, and M. Q. Islam (2014), "Design and analysis of a low cost solar water pump for irrigation in bangladesh," Journal of Mechanical Engineering, vol. 43, no. 2.

8. H. Biswas and F. Hossain (2013), "Solar Pump: A Possible Solution of Irrigation and Electric Power Crisis of Bangladesh," International Journal of Computer Applications, vol. 62, no. 16, pp. 1-5.

9. R. Leyva, C. Alonso, I. Queinnec, A. Cid-Pastor, D. Lagrange, and L. Martinez-Salamero (2006), "Mppt of photovoltaic systems using extremum - seeking control," Aerospace and Electronic Systems, IEEE Transactions on, vol. 42, no. 1, pp. 249 - 258.

10. Roger, A, M and Jerry, V (2005) "Photovoltaic systems engineering" 2nd edition, Taylor \& Francis e-Library.

\section{AUTHORS PROFILE}

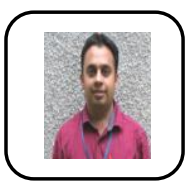

Mr. Ravi Kumar P. Received his Bachelor's Degree in Electrical and Electronics Engineering from Anna University Chennai in 2009, Master's Degree in Electrical Drives and Embedded Control from Anna University of Technology Coimbatore in 2011. He is pursuing his Ph.D in the area of power electronics from Anna University Chennai. He has six years of teaching experience. He has published 4 papers in International Journals, 2 in International Conferences and 4 in National Conferences. He also handles workshop on MatLab, LabView, MagNet and ElecNet. His research interests are Electromagnetic Interference, multi port converter configurations and battery powered electric vehicle.

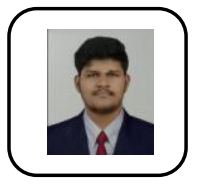

Akash B. Electrical and Electronics Engineering (UG Scholar) KPR Institute of Engineering and Technology Coimbatore,India

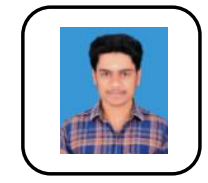

HariKrishnan R. Electrical and Electronics Engineering (UG Scholar) KPR Institute of Engineering and Technology Coimbatore, India

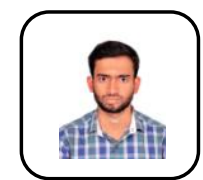

LakshmiNarayanan S. Electrical and Electronics Engineering (UG Scholar) KPR Institute of Engineering and Technology Coimbatore, India

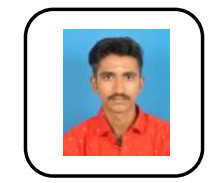

Arunodhayan N. Electrical and Electronics Engineering (UG Scholar) KPR Institute of Engineering and Technology Coimbatore, India

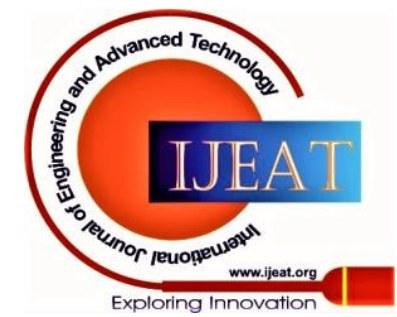

